\title{
The influence of frailty syndrome on medication adherence among elderly patients with hypertension
}

\author{
Beata Jankowska-Polańska' \\ Krzysztof Dudek ${ }^{2}$ \\ Anna Szymanska- \\ Chabowska ${ }^{3}$ \\ Izabella Uchmanowicz' \\ 'Department of Clinical Nursing, \\ Faculty of Health Science, Wroclaw \\ Medical University, ${ }^{2}$ Department \\ of Logistic and Transport Systems, \\ Faculty of Mechanical Engineering, \\ Wroclaw University of Technology, \\ ${ }^{3}$ Department of Internal Medicine, \\ Occupational Diseases, Hypertension \\ and Clinical Oncology, Wroclaw \\ Medical University, Wroclaw, Poland
}

Correspondence: Beata JankowskaPolańska

Department of Clinical Nursing, Faculty of Health Science, Wroclaw Medical University, 5 Bartla Street, 5I-6I8

Wroclaw, Poland

Tel +48 7 I 93477007

Email bianko@poczta.onet.pl
This article was published in the following Dove Press journal:

Clinical Interventions in Aging

7 December 2016

Number of times this article has been viewed

Background: Hypertension affects about $80 \%$ of people older than 80 years; however, diagnosis and treatment are difficult because about $55 \%$ of them do not adhere to treatment recommendations due to low socioeconomic status, comorbidities, age, physical limitations, and frailty syndrome.

Aims: The purposes of this study were to evaluate the influence of frailty on medication adherence among elderly hypertensive patients and to assess whether other factors influence adherence in this group of patients.

Methods and results: The study included 296 patients (mean age 68.8 18.0 ) divided into frail $(n=198)$ and non-frail ( $n=98)$ groups. The Polish versions of the Tilburg Frailty Indicator (TFI) for frailty assessment and 8-item Morisky Medication Adherence Scale for adherence assessment were used. The frail patients had lower medication adherence in comparison to the non-frail subjects $(6.60 \pm 1.89$ vs $7.11 \pm 1.42 ; P=0.028)$. Spearman's rank correlation coefficients showed that significant determinants with negative influence on the level of adherence were physical (rho $=-0.117$ ), psychological (rho $=-0.183$ ), and social domain (rho $=-0.163$ ) of TFI as well as the total score of the questionnaire (rho $=-0.183$ ). However, multiple regression analysis revealed that only knowledge about complications of untreated hypertension $(\beta=0.395)$ and satisfaction with the home environment $(\beta=0.897)$ were found to be independent stimulants of adherence level.

Conclusion: Frailty is highly prevalent among elderly hypertensive patients. Higher level of frailty among elderly patients can be considered as a determinant of lower adherence. However, social support and knowledge about complications of untreated hypertension are the most important independent determinants of adherence to pharmacological treatment.

Keywords: frailty syndrome, ageing, hypertension, medication adherence, geriatric syndrome

\section{Introduction}

In the coming decades, the percentage of elderly people will rapidly increase, while the percentage of population of working age will decrease. Although prolongation of life is a positive effect, the aging population is a challenge for health care systems. Due to aging, the importance of cardiovascular disease (CVD) as the leading cause of death in adults becomes very important. According to the Seventh Report of the Joint National Committee on Prevention, Detection, Evaluation and Treatment of High Blood Pressure, hypertension occurs in more than two-thirds of individuals older than 50 years. ${ }^{1}$ POLSENIOR study ${ }^{2}$ reveals that in population older than 80 years, hypertension affects about a million people. If the observed increase continues, the 
number of elderly hypertensive patients will increase by $50 \%$ by $2035 .{ }^{3}$ Increase in prevalence of hypertension along with age is mainly caused by demographic changes.

Application of antihypertensive therapy in individuals older than 50 years reduces the risk of strokes, limits exacerbations of heart insufficiency, and lowers mortality due to CVDs. ${ }^{3}$ In elderly people (according to the World Health Organization [WHO] over the age of 65 years, while according to UN over the age of 60 years), proper diagnosis and treatment of hypertension are difficult. ${ }^{4}$ Older patients require careful pharmacotherapy with low doses of drugs and monotherapy, and in case of ineffectiveness, increase the dose or introduce another antihypertensive drug. Patient adherence and regular drug intake are prerequisites for effective therapy, especially in older age. ${ }^{5}$ A degree of adherence depends on patients' involvement in the therapeutic process, understanding of the therapeutic goals, and well-being during treatment. Among the most frequent reasons for skipping doses of medication and non-compliance with the recommendations include: side effects, financial Reasons, old age, comorbidities, reduced physical, and cognitive abilities, strength, and proper cognitive Functioning (frailty syndrome [FS]). ${ }^{6}$ About $55 \%$ of elderly patients do not adhere to therapeutic plan. ${ }^{7}$ Medication nonadherence is cited as the primary cause for lack of hypertension control. ${ }^{8}$ Due to physiological changes progressing with age and comorbidities, treatment of hypertension in elderly patients is a challenge for the entire therapeutic team.

What is characteristic in elderly patients is the occurrence of geriatric syndrome (GS), which gradually leads to functional disability and lowers quality of life. GSs, which commonly include frailty, dementia, delirium, incontinence, falls, and dizziness, are highly prevalent, multifactorial, and associated with substantial morbidity, hospitalization, and poor outcomes. Nevertheless, this central geriatric concept has remained poorly defined. Understanding basic mechanisms involved in GSs will be critical to advancing research and developing targeted therapeutic options, although given the complexity of these multifactorial conditions, attempts to define relevant mechanisms will need to incorporate more complex models, including a focus on synergistic interactions between different risk factors. ${ }^{9}$ It may be assumed that GS could modify the medication status of elderly hypertensive patients.

In the recent years, FS in elderly patients has become widely discussed. It develops in $15 \%-20 \%$ of patients older than 60 years and in $30 \%$ of patients older than 80 years. ${ }^{9}$ FS has been implicated as a causative and prognostic factor in patients with CVD. The American Heart Association and the Society of Geriatric Cardiology have called for a better understanding of frailty as it pertains to cardiac care in the elderly. Patients diagnosed with FS are at a higher risk of falling, decreased mobility, decreased ability to perform the basic activities of daily living, frequent hospitalizations, and death. ${ }^{10}$ In all, $25 \%-50 \%$ of cardiac patients suffer from FS. ${ }^{9}$

Some studies have also shown that the assessment of frailty can delay the development of disability and reduce the need for institutionalization and nursing care among elderly people living at home. ${ }^{11,12}$ Chao et al demonstrated that the absence of frailty/pre-frailty and presence of polypharmacy were significantly associated with poorer medication adherence. ${ }^{13}$

Research studies available indicate that despite the availability of effective medical therapy, over half of all hypertensives do not take any treatment and more than half of those on treatment have blood pressures over the 140/90 mmHg threshold. ${ }^{14}$ WHO describes poor adherence as the most important cause of uncontrolled blood pressure and estimates that $50 \%-70 \%$ of people do not take their antihypertensive medication as prescribed. ${ }^{15}$

There is research available that emphasizes the negative influence of sociodemographic and clinical variables on adherence to treatment recommendations. Medication adherence rates have been shown to be related to age, sex, race, geographical region of residence, and illness perceptions. ${ }^{16}$ The psychosocial factors that strongly correlate with nonadherence include depression, lack of social support, and low quality of life. ${ }^{17}$ Only a few studies are available on the relation between the GS and medication adherence. They pertain to chronic diseases other than hypertension. ${ }^{13,18}$ There is a discussion in the research available on the relation between age and medication adherence. Some studies have shown that younger patients display higher adherence, ${ }^{16,19,20}$ while others indicate that young age is a determinant of poor adherence to hypotensive medication. ${ }^{21,22}$ Several authors report higher adherence in elderly patients, ${ }^{17,23-25}$ which can be explained by the presence of comorbidities, making the patients perceive themselves as very ill and take the prescribed treatment seriously. ${ }^{22}$

Considering the increasing age of patients with hypertension and contradictory study results regarding the effect of age on adherence, a special approach to their treatment is required with more attention paid to GS.

The purposes of this study were to evaluate the influence of frailty as a component of GS on medication adherence among elderly patients with hypertension and to assess whether other factors (especially polypharmacy as a 
component of GS) influence adherence to treatment in this group of patients.

\section{Methods}

The study was performed in the outpatient clinic Kosmonautów in Wroclaw, Poland. Data were collected between January 2015 and November 2015. The study included consecutive 296 patients (131/45.3\% men, 165/55.7\% women) with a mean age of $68.8 \pm 8.0$ years diagnosed with hypertension. Inclusion criteria were as follows: 1) clinically confirmed hypertension, 2) written informed consent, and 3 ) age $\geq 60$ years. Exclusion criteria were as follows: 1) moderate to severe dementia (defined as Mini-Mental score $\leq 15),{ }^{26}$ 2) previous stroke, and 3) lack of consent to participation in the study.

Patients were selected by a panel consisting of a physician and a nurse - specialist in the field of cardiac nursing. All patients received information about the purposes and nature of the study and provided written informed consent to participate in the study.

The sample group was homogeneous and suitable for statistical analysis.

\section{Instruments}

Sociodemographic data (age, sex, education, and marital status) and clinical data (hypertension level according to the European Society of Cardiology, comorbidities, duration of hypertension, blood pressure monitoring, number and methods of taking medications, and method of non-pharmacological treatment) were obtained from patients' records and during personal interviews performed by a nurse.

The spectrum of GS is expanding, and the definitions of each component are constantly evolving. In the present study, we included the following GS for analysis: frailty and polypharmacy, whose influence on the prognosis had already been documented. ${ }^{13,27}$

Frailty was measured using the Polish version of the Tilburg Frailty Indicator (TFI), which consists of two parts. ${ }^{28}$ One addresses sociodemographic characteristics of a participant (sex, age, marital status, country of origin, educational level, and monthly income) and other potential determinants of frailty (lifestyle, multimorbidity, life events, and home living environment). The second part addresses components of frailty and comprises 15 self-reported questions, divided into three domains. The physical domain ( $0-8$ points) consists of eight questions related to physical health, unexplained weight loss, difficulty in walking, balance, hearing problems, vision problems, strength in hands, and physical tiredness. The psychological domain ( $0-4$ points $)$ comprises four items related to cognition, depressive symptoms, anxiety, and coping. The social domain ( $0-3$ points) comprises three questions related to living alone, social relations, and social support. Eleven items of part two of the TFI have two response categories (yes and no), while the remaining items have three (yes, no, and sometimes). "Yes" or "sometimes" responses are scored 1 point each, while "no" responses are scored 0 . The instrument's total score may range from 0 to 15; the higher the score, the higher the patient's frailty. Frailty is diagnosed when the total TFI score is $\geq 5$. Previous studies have suggested that the TFI is a valid and reliable instrument for measuring frailty. ${ }^{28,29}$ Adherence to treatment was assessed using the Polish version of 8-item Morisky Medication Adherence Scale (MMAS-8). The self-reported MMAS-8 tool is an 8-item tool, simple to administer, reliable, and economical for use in clinical practice. The MMAS-8 was designed to facilitate the identification of barriers and behaviors associated with adherence to chronic medication. The tool has been determined to be reliable and significantly associated with blood pressure control in individuals with hypertension, as well as with antihypertensive medication pharmacy fill rates. Scores on the MMAS- 8 range from 0 to 8 , with scores of less than 6 reflecting low adherence, 6 to $<8$ reflecting medium, and 8 reflecting high adherence. ${ }^{30-32}$

\section{Statistical analysis}

For the quantitative variables, verification of empirical normality distribution was tested by Shapiro-Wilk test. Mean and standard deviations (SDs) were calculated. For comparisons of means between the two groups of patients, one-way analysis of variance was used. In case of rejection of the null hypothesis of no differences in the groups, post hoc test with the method of the least significant difference was used.

Qualitative and ordinal variables were grouped in crosstabulation table - the number of cases was summed for each category and the percentage was calculated. Independence of qualitative variables was verified by Pearson chi-square test. For evaluation of the strength and significance of associations, Spearman's rank correlation coefficient (rho) was used.

To test the influence of independent variables on the level of adherence, linear regression was used (general stepwise regression). Prior to regression analysis, assumption of applicability of least squares method was checked as well as outliers were detected. For predictor variables (frailty index and age), standardized coefficient $\beta$ and regression coefficient $b$ were calculated. Statistical significance of given variables in the model was tested by Student's $t$-test. The quality of 
proposed linear regression model was checked by standard error of estimate.

Statistical analysis was carried out with computer package Statistica software v.10 (StatSoft Inc., Tulsa, OK, USA).

The study was approved by the Bioethics Committee of Wroclaw Medical University (approval no KB 521/2014) and it conforms to the principles outlined in the Declaration of Helsinki.

\section{Results}

The analysis of FS with Tilburg questionnaire for the entire group of 296 patients showed that the mean level of physical domain score was 3.31 ( $\mathrm{SD}=2.21)$, mean level of psychological domain was $1.79(\mathrm{SD}=1.07)$, and mean level of social domain was $1.02(\mathrm{SD}=0.83)$. The mean total TFI score was $6.11(\mathrm{SD}=3.12)$ with the range from 0 to 14 scores. On this basis, patients were classified into the following two groups: 1) frail (TFI $\geq 5$ ), $\mathrm{n}=198$ and 2) non-frail (TFI <5), $\mathrm{n}=98$. Tilburg questionnaire domain scores for patients from the frail group were statistically significantly higher compared to those from the non-frail group. This indicates that in these patients FS was more intense. The results are presented in Table 1.

\section{Sociodemographic characteristics of patients with hypertension with respect to FS}

Patients from the frail group were older (70.0 $18.2 \mathrm{vs}$ $66.3 \pm 7.1$ years; $P<0.001$ ) and more often professionally inactive (retired: $58.1 \%$ vs $48 \%$; disabled $17.7 \%$ vs $12.2 \%$; $P=0.025)$. Majority of them were single/divorced/alone (43.9\% vs $32.7 \% ; P=0.122)$; they were more often living alone $(26.3 \%$ vs $9.2 \% ; P=0.004)$. Frail patients had lower household income per capita and almost $60 \%$ of them received less than 1,500 PLN, while similar group of non-frail subjects $(66 \%)$ received more than 1,500 PLN. Frail patients are considerably more likely to experience a traumatic or stressful event such as serious illness (40.9\%), and partner's severe disease $(32.8 \%)$ or partner's death $(25.3 \%)$ than nonfrail subjects. (Table 2).

Table I Clinical characteristics of patients with hypertension in relation to frailty syndrome

\begin{tabular}{|c|c|c|c|c|c|c|c|}
\hline Variable & $\begin{array}{l}\text { Total } \\
\mathrm{N}=296\end{array}$ & $\%$ & $\begin{array}{l}\text { Frail } \\
N=198\end{array}$ & $\%$ & $\begin{array}{l}\text { Non-frail } \\
\mathrm{N}=98\end{array}$ & $\%$ & $P$-value \\
\hline Tilburg frailty indicator, $M \pm S D$ & $6.11 \pm 3.12$ & & $9.33 \pm 0.5$ & & $3.21 \pm 3.06$ & & $<0.001$ \\
\hline Physical components, $\mathrm{M} \pm \mathrm{SD}$ & $3.3 I \pm 2.21$ & & $5.78 \pm 1.7$ & & $2.56 \pm 1.8$ & & \\
\hline Psychological components, $\mathrm{M} \pm \mathrm{SD}$ & $1.79 \pm 1.07$ & & $2.83 \pm 0.7$ & & $1.03 \pm 0.4$ & & \\
\hline Social components, $\mathrm{M} \pm \mathrm{SD}$ & $1.02 \pm 0.83$ & & $1.86 \pm 0.6$ & & $0.84 \pm 0.3$ & & \\
\hline Duration of hypertension, $M \pm S D$ & $12.3 \pm 8.8$ & & $12.6 \pm 9.0$ & & II.7 \pm 8.2 & & 0.362 \\
\hline \multicolumn{8}{|l|}{ Comorbidities } \\
\hline Diabetes mellitus & 108 & $36.5 \%$ & 79 & $39.9 \%$ & 29 & $29.6 \%$ & 0.084 \\
\hline Ischemic heart disease & 77 & $26.0 \%$ & 56 & $28.3 \%$ & 21 & $21.4 \%$ & 0.204 \\
\hline Renal insufficiency & 48 & $16.2 \%$ & 33 & $16.7 \%$ & 15 & $15.3 \%$ & 0.759 \\
\hline Chronic obstructive pulmonary disease & 74 & $25.0 \%$ & 52 & $26.3 \%$ & 22 & $22.4 \%$ & 0.466 \\
\hline \multicolumn{8}{|l|}{ Diary of self-control blood pressure } \\
\hline Yes & 168 & $56.8 \%$ & 118 & $59.6 \%$ & 50 & $51.0 \%$ & 0.202 \\
\hline Frequency of taking drugs & & & & & & & 0.044 \\
\hline More often than once a day & 86 & $45.3 \%$ & 64 & $47.8 \%$ & 22 & $39.3 \%$ & \\
\hline Once a day & 104 & $54.8 \%$ & 70 & $52.2 \%$ & 34 & $60.7 \%$ & \\
\hline Knowledge of complications of untreated hypertension & 164 & $55.4 \%$ & 111 & $56.1 \%$ & 53 & $54.1 \%$ & 0.843 \\
\hline Knowledge of drug side effects & 104 & $35.1 \%$ & 69 & $34.8 \%$ & 35 & $35.7 \%$ & 0.986 \\
\hline Classification of blood pressure level according to ESC & & & & & & & 0.004 \\
\hline Normal & 21 & $7.1 \%$ & II & $5.6 \%$ & 10 & $10.2 \%$ & \\
\hline High normal & 53 & $17.9 \%$ & 20 & $12.1 \%$ & 29 & $29.6 \%$ & \\
\hline Grade I hypertension & 148 & $53.4 \%$ & 109 & $55 \%$ & 39 & $39.8 \%$ & \\
\hline Grade II hypertension & 74 & $25 \%$ & 54 & $27.3 \%$ & 20 & $20.4 \%$ & \\
\hline \multicolumn{8}{|l|}{ Drugs taken } \\
\hline Angiotensin-converting enzyme inhibitors & 132 & $44.6 \%$ & 85 & $42.9 \%$ & 47 & $48 \%$ & 0.107 \\
\hline$\beta$-Blockers & 82 & $27.7 \%$ & 61 & $30.8 \%$ & 21 & $21.4 \%$ & 0.045 \\
\hline Angiotensin II receptor antagonist & 17 & $5.7 \%$ & 15 & $7.6 \%$ & 2 & $2.0 \%$ & 0.064 \\
\hline Thiazide-like diuretics & 55 & $18.6 \%$ & 32 & $16.2 \%$ & 23 & $23.5 \%$ & 0.502 \\
\hline Calcium antagonists & 91 & $30.7 \%$ & 57 & $28.8 \%$ & 34 & $34.7 \%$ & 0.313 \\
\hline \multicolumn{8}{|l|}{ Type of therapy } \\
\hline Monotherapy & 169 & $57.1 \%$ & 109 & $55.1 \%$ & 60 & $61.2 \%$ & 0.627 \\
\hline Polypharmacy & 96 & $32.4 \%$ & 75 & $37.9 \%$ & 21 & $21.4 \%$ & 0.047 \\
\hline
\end{tabular}

Notes: Use of the CMMAS is protected by US and International copyright laws. Permission for use is required. A license agreement is available from: Donald E Morisky, ScD, ScM, MSPH, Professor, Department of Community Health Sciences, UCLA School of Public Health, 650 Charles E. Young Drive South, Los Angeles, CA 90095- I772. ${ }^{30-32}$ Abbreviations: N, sample size; $P$, significance level; ESC, European Society of Cardiology; M, mean; SD, standard deviation. 
Table 2 Sociodemographic and clinical characteristics of patients with hypertension with respect to frailty syndrome

\begin{tabular}{|c|c|c|c|c|c|c|c|}
\hline Variable & $\begin{array}{l}\text { Total } \\
\mathrm{N}=296\end{array}$ & $\%$ & $\begin{array}{l}\text { Frail } \\
N=198\end{array}$ & $\%$ & $\begin{array}{l}\text { Non-frail } \\
\mathrm{N}=98\end{array}$ & $\%$ & $P$-value \\
\hline Age (years), $M \pm S D$ & $68.8 \pm 8.0$ & & $70.0 \pm 8.2$ & & $66.3 \pm 7.1$ & & $<0.001$ \\
\hline Female sex & 165 & $55.7 \%$ & 115 & $58.1 \%$ & 50 & $51.0 \%$ & 0.305 \\
\hline Marital status & & & & & & & 0.050 \\
\hline Married/living with partner & 177 & $59.8 \%$ & 111 & $56.1 \%$ & 66 & $67.3 \%$ & \\
\hline Single/divorced & 118 & $40.2 \%$ & 87 & $43.9 \%$ & 32 & $32.7 \%$ & \\
\hline Education & & & & & & & 0.122 \\
\hline None or primary & 98 & $33.1 \%$ & 73 & $36.9 \%$ & 25 & $25.5 \%$ & \\
\hline Secondary & 138 & $46.6 \%$ & 89 & $44.9 \%$ & 49 & $50.0 \%$ & \\
\hline University & 60 & $20.3 \%$ & 36 & $18.2 \%$ & 24 & $24.5 \%$ & \\
\hline Professional activity & & & & & & & 0.025 \\
\hline Employed & 82 & $27.7 \%$ & 44 & $22.2 \%$ & 38 & $38.8 \%$ & \\
\hline Retired/disabled & 209 & $70.6 \%$ & 150 & $75.8 \%$ & 59 & $60.2 \%$ & \\
\hline Unemployed & 5 & $1.7 \%$ & 4 & $2.0 \%$ & I & $1.0 \%$ & \\
\hline \multicolumn{8}{|l|}{ Lives with } \\
\hline Alone & 61 & $20.6 \%$ & 52 & $26.3 \%$ & 9 & $9.2 \%$ & 0.004 \\
\hline With spouse/partner & 231 & $51.4 \%$ & 143 & $72.2 \%$ & 88 & $89.8 \%$ & 0.216 \\
\hline In organized senior center & 4 & $1.3 \%$ & 3 & $1.5 \%$ & I & $1.0 \%$ & 0.135 \\
\hline \multicolumn{8}{|l|}{ Household income per capita (PLN) } \\
\hline $600-900$ & 23 & $7.8 \%$ & 19 & $9.6 \%$ & 4 & $4.0 \%$ & \\
\hline $90 I-I, 200$ & 77 & $26.0 \%$ & 64 & $32.3 \%$ & 13 & $13.3 \%$ & \\
\hline$I, 20 I-1,500$ & 57 & $19.3 \%$ & 41 & $20.7 \%$ & 16 & $16.3 \%$ & $<0.001$ \\
\hline$I, 50 \mathrm{I}-\mathrm{I}, 800$ & 53 & $17.9 \%$ & 24 & $12.1 \%$ & 29 & $29.6 \%$ & \\
\hline $\mathrm{I}, 80 \mathrm{I}-2, \mathrm{I} \mid 00$ & 36 & $12.2 \%$ & 21 & $10.6 \%$ & 15 & $15.3 \%$ & \\
\hline Over 2,100 & 50 & $16.9 \%$ & 29 & $14.6 \%$ & 21 & $21.4 \%$ & \\
\hline \multicolumn{8}{|l|}{ Traumatic/stressful events during the past year } \\
\hline Death of a loved one & 60 & $20.3 \%$ & 50 & $25.3 \%$ & 10 & $10.2 \%$ & 0.004 \\
\hline Serious illness & 94 & $31.8 \%$ & 81 & $40.9 \%$ & 13 & $13.3 \%$ & $<0.001$ \\
\hline Serious illness in a loved one & 75 & $25.3 \%$ & 65 & $32.8 \%$ & 10 & $10.2 \%$ & $<0.001$ \\
\hline Divorce or ending of an important intimate relationship & 20 & $6.8 \%$ & 19 & $9.6 \%$ & I & $1.0 \%$ & 0.005 \\
\hline Traffic accident & 23 & $7.8 \%$ & 21 & $10.6 \%$ & 2 & $2.0 \%$ & 0.010 \\
\hline \multicolumn{8}{|l|}{ Are you satisfied with your home living environment? } \\
\hline Yes & 261 & $88.2 \%$ & 168 & $84.8 \%$ & 93 & $94.9 \%$ & 0.012 \\
\hline
\end{tabular}

Abbreviations: $N$, sample size; $M$, mean; $S D$, standard deviation; $P$, significance level.

\section{Clinical characteristic of patients with hypertension with respect to FS}

Patients with hypertension less often reported normal blood pressure values (5.6\% vs $10.2 \%)$ and majority of them were diagnosed with stage I ( $55 \%$ vs $39.8 \%)$ or stage II $(27.3 \%$ vs $20.4 \% ; P=0.04$ ) hypertension. Frail patients prevailed in a group of 169 patients who were treated with monotherapy (61.2\% vs $55.1 \%$; not significant). Frail patients also prevailed in a group of 96 patients who were treated with several medicines at a time ( $37.9 \%$ vs $21.4 \% ; P=0.047)$ and considerably gave way to non-frail patients in a group of 31 patients who received polytherapy in one tablet $(7.1 \%$ vs $17.4 \% ; P=0.021)$. Frail patients more often took beta-blockers than non-frail ones $(30.8 \%$ vs $21.4 \%)$. In terms of other variables, no statistically significant differences were found between frail and non-frail patients. Data are shown in Table 1.

\section{Analysis of the level of adherence in relation to FS}

The analysis of the level of adherence with MMAS-8 questionnaire showed that frail subjects received lower score of adherence in comparison to non-frail subjects ( $6.60 \pm 1.89$ vs $7.11 \pm 1.42 ; P=0.028$ ). In the frail group, $21 \%$ of patients had low level of adherence, while in the nonfrail group, only $12.3 \%$ of studied subjects had low level of adherence (Table 3).

\section{Univariate analysis - the impact of the studied factors on the level of adherence (MMAS-8 score)}

Next, Spearman's rank correlation coefficient was calculated in order to assess the influence of selected variables on the level of adherence (MMAS-8); the results are presented in Table 4. The analysis of correlations showed that some 
Table 3 Analysis of the level of adherence (MMAS-8) in relation to frailty syndrome

\begin{tabular}{|c|c|c|c|c|c|c|c|}
\hline Variable & $\begin{array}{l}\text { Total } \\
\mathbf{N}=296\end{array}$ & & $\begin{array}{l}\text { Frail } \\
\mathrm{N}=198\end{array}$ & & $\begin{array}{l}\text { Non-frail } \\
\mathrm{N}=98\end{array}$ & & $P$-value \\
\hline QI. Do you sometimes forget to take your antihypertensive pills? (No) & 224 & $75.7 \%$ & 140 & $70.7 \%$ & 84 & $85.7 \%$ & 0.007 \\
\hline $\begin{array}{l}\text { Q2. People sometimes miss taking their medications for reasons other than } \\
\text { forgetting. Thinking over the past } 2 \text { weeks: were there any days when you did } \\
\text { not take your antihypertensive medicine? (No) }\end{array}$ & 260 & $87.8 \%$ & 168 & $84.8 \%$ & 92 & $93.9 \%$ & 0.041 \\
\hline $\begin{array}{l}\text { Q3. Have you ever cut back or stopped taking your medication without telling } \\
\text { your doctor, because you felt worse when you took it? (No) }\end{array}$ & 255 & $86.2 \%$ & 170 & $85.9 \%$ & 85 & $86.7 \%$ & 0.979 \\
\hline $\begin{array}{l}\text { Q4. When you travel or leave home, do you sometimes forget to bring along your } \\
\text { antihypertensive medicine? (No) }\end{array}$ & 236 & $79.7 \%$ & 153 & $77.3 \%$ & 83 & $84.7 \%$ & 0.180 \\
\hline Q5. Did you take your antihypertensive medicine yesterday? (Yes) & 252 & $85.1 \%$ & 169 & $85.4 \%$ & 83 & $84.7 \%$ & 0.981 \\
\hline $\begin{array}{l}\text { Q6. When you feel like your antihypertensive is under control, do you sometimes } \\
\text { stop taking your medicine? (No) }\end{array}$ & 250 & $84.5 \%$ & $|6|$ & $81.3 \%$ & 89 & $90.8 \%$ & 0.034 \\
\hline $\begin{array}{l}\text { Q7. Taking medication everyday is a real inconvenience for some people. Do you } \\
\text { ever feel hassled about sticking to your antihypertensive treatment plan? (No) } \\
\text { O8. How often do you have difficulty remembering to take all your medications? }\end{array}$ & 257 & $86.8 \%$ & 167 & $83.4 \%$ & 90 & $91.8 \%$ & 0.106 \\
\hline $\begin{array}{l}\text { Q8. How often do you have difficulty remembering to take all your medications? } \\
\text { Never/rarely }\end{array}$ & 4 & $1.4 \%$ & 3 & $1.5 \%$ & 1 & $1.0 \%$ & 0.744 \\
\hline Sometimes & 24 & $8.1 \%$ & 18 & $9.1 \%$ & 6 & $6.1 \%$ & \\
\hline Usually & 43 & $14.5 \%$ & 30 & $15.2 \%$ & 13 & $13.3 \%$ & \\
\hline All the times & 225 & $76.0 \%$ & 147 & $74.2 \%$ & 78 & $79.6 \%$ & \\
\hline MMAS-8 score & & & & & & & \\
\hline $\begin{array}{l}M \pm S D \\
M e(Q I ; Q 3) \\
M i n-\max \end{array}$ & $\begin{array}{l}6.77 \pm 1.76 \\
7(6.5 ; 8) \\
0.75-8\end{array}$ & & $\begin{array}{l}6.60 \pm 1.89 \\
7(6 ; 8) \\
1-8\end{array}$ & & $\begin{array}{l}7.11 \pm 1.42 \\
8(7 ; 8) \\
0.75-8\end{array}$ & & 0.028 \\
\hline Adherence level & & & & & & & \\
\hline $\begin{array}{l}\text { Low } \\
\text { Medium }\end{array}$ & $\begin{array}{l}54 \\
111\end{array}$ & $\begin{array}{l}18.2 \% \\
37.5 \%\end{array}$ & $\begin{array}{l}42 \\
75\end{array}$ & $\begin{array}{l}21.2 \% \\
37.9 \%\end{array}$ & $\begin{array}{l}12 \\
36\end{array}$ & $\begin{array}{l}12.3 \% \\
36.7 \%\end{array}$ & 0.109 \\
\hline High & 131 & $44.3 \%$ & 81 & $40.9 \%$ & 50 & $51.0 \%$ & \\
\hline
\end{tabular}

Notes: Use of the OMMAS is protected by US and International copyright laws. Permission for use is required. A license agreement is available from: Donald E Morisky, ScD, ScM, MSPH, Professor, Department of Community Health Sciences, UCLA School of Public Health, 650 Charles E. Young Drive South, Los Angeles, CA 90095- 1772.30-32 Abbreviations: MMAS-8, 8-item Morisky Medication Adherence Scale; N, sample size; $P$, significance level; M, mean; SD, standard deviation; Min, minimum; max; maximum; Me, median.

variables such as marital status (rho $=0.132$ ), satisfaction with the home living environment ( $\mathrm{rho}=0.169)$, knowledge about complications $($ rho $=0.116)$, and treatment with angiotensin receptor antagonist (rho $=0.120$ ) had significant positive association with adherence, while living alone ( $r h o=-0.117)$, traumatic/stressful event in the last year: death of a spouse (rho $=-0.138)$, serious illness (rho $=-0.117)$, serious illness in a spouse/partner (rho $=-0.178$ ), divorce (rho $=-0.140$ ),

Table 4 Spearman's rank correlation coefficients of analyzed component of Tilburg questionnaire with the level of adherence (MMAS-8)

\begin{tabular}{lllll}
\hline $\begin{array}{l}\text { Determinants (variable)/ } \\
\text { TFI component }\end{array}$ & Rho & $\boldsymbol{P}$-value & Beta & $\boldsymbol{P}$-value \\
\hline TFI - score & & & & \\
TFI - physical component & -0.183 & $\mathbf{0 . 0 0 2}$ & 0.069 & 0.292 \\
TFI - psychological component & -0.183 & $\mathbf{0 . 0 0 2}$ & -0.212 & 0.118 \\
TFI - social component & -0.163 & $\mathbf{0 . 0 0 5}$ & 0.069 & 0.775 \\
\hline
\end{tabular}

Notes: Data in bold indicates statistical significance $(P<0.05)$. Use of the @MMAS is protected by US and International copyright laws. Permission for use is required. A license agreement is available from: Donald E Morisky, ScD, ScM, MSPH, Professor, Department of Community Health Sciences, UCLA School of Public Health, 650 Charles E. Young Drive South, Los Angeles, CA 90095- I772. ${ }^{30-32}$

Abbreviations: MMAS-8, 8-item Morisky Medication Adherence Scale; TFI, Tilburg frailty indicator; Rho, Spearman's rank correlation coefficients; Beta, regression coefficient; $P$, significance level. and traffic accident (rho $=-0.120$ ) had negative association with adherence (Table 5).

\section{Spearman's rank correlation coefficients of analyzed component of Tilburg questionnaire with the level of adherence}

Spearman's rank correlation coefficients calculated for components of Tilburg questionnaire showed that significant determinants with negative influence on the level of adherence (MMAS-8) were physical (rho $=-0.117$ ), psychological (rho $=-0.183$ ), and social domain ( $r h o=-0.163$ ) of Tilburg questionnaire as well as the total score of the questionnaire (rho $=-0.183$ ) (Table 4).

As a result of the analysis of multiple regression, independent stimulants to the level of adherence such as knowledge about complications $(\beta=0.395)$ and satisfaction with the home environment $(\beta=0.897)$ were found, while it is surprising that none of the components of Tilburg questionnaire was a statistically significant independent determinant lowering the level of adherence. The model appeared to be significant: $\mathrm{F}(4 ; 291)=8.17 ; P<0.0001$. Adherence $=6.2+0.39$ $\times$ knowledge about complications $+0.90 \times$ satisfaction with 
Table 5 Spearman's rank correlation coefficients of analyzed sociodemographic and clinical variables with the level of adherence

\begin{tabular}{|c|c|c|c|c|}
\hline Determinant (variable) & Rho & $P$-value & Beta & P-value \\
\hline Age, years & -0.084 & 0.150 & & \\
\hline Sex & -0.068 & 0.242 & & \\
\hline Duration of a disease & 0.006 & 0.919 & & \\
\hline Marital status (married/in a relation) & 0.132 & 0.023 & 0.269 & 0.205 \\
\hline Higher education & 0.052 & 0.371 & & \\
\hline Professional activity & 0.009 & 0.881 & & \\
\hline Living alone & -0.117 & 0.044 & -0.292 & 0.270 \\
\hline Severity of hypertension & 0.093 & 0.110 & & \\
\hline Diabetes mellitus & 0.008 & 0.891 & & \\
\hline Ischemic heart disease & -0.076 & 0.190 & & \\
\hline Renal insufficiency & 0.012 & 0.856 & & \\
\hline Knowledge about complications of untreated hypertension & 0.116 & 0.047 & 0.395 & 0.045 \\
\hline Knowledge about drug side effects & 0.033 & 0.574 & & \\
\hline Treatment with angiotensin-converting enzyme inhibitors & 0.003 & 0.956 & & \\
\hline Treatment with $\beta$-blockers & -0.072 & 0.217 & & \\
\hline Treatment with angiotensin II receptor antagonist & 0.120 & 0.039 & 0.649 & 0.123 \\
\hline Treatment with thiazide-like diuretics & -0.075 & 0.197 & & \\
\hline Treatment with calcium antagonists & 0.063 & 0.280 & & \\
\hline Monotherapy & -0.092 & 0.115 & & \\
\hline Death of a loved one during the past year & -0.138 & 0.018 & 0.014 & 0.963 \\
\hline Serious illness during the past year & -0.117 & 0.044 & -0.075 & 0.751 \\
\hline Serious illness in a loved one during the past year & -0.178 & 0.002 & -0.154 & 0.573 \\
\hline Divorce or ending of an important intimate relationship during the past year & -0.140 & 0.016 & 0.082 & 0.873 \\
\hline Traffic accident during the past year & -0.120 & 0.038 & -0.281 & 0.557 \\
\hline Satisfaction with the home living environment & 0.169 & 0.004 & 0.897 & 0.007 \\
\hline
\end{tabular}

Notes: Data in bold indicates statistical significance $(P<0.05)$.

Abbreviations: Rho, Spearman's rank correlation coefficients; Beta, regression coefficient; $P$, significance level.

the home environment. The model predicts $10.1 \%$ of variability of adherence $\left(R^{2}=0.101\right)$. The standard error of estimation was 1.68 (Table 4 ).

\section{Discussion}

Poor adherence to prescribed medications reduces treatment benefits and can lower the clinician's assessment of therapeutic effectiveness. Non-adherence is thought to account for $30 \%-50 \%$ of treatment failures. ${ }^{33}$ Non-adherence leads to worse medical treatment outcomes such as higher hospitalization rates, institutionalization for the frail elderly patients, and increased health care costs. ${ }^{33-36}$

An improved understanding of the determinants associated with medication adherence and health behaviors has become an important outcome in management strategies for hypertension patients. Effective identification of patients at risk of pharmacological non-adherence might be particularly helpful in planning interventions to enhance illness control, prevent complications, improve long-term treatment outcomes, and limit adverse outcomes in these patients. ${ }^{13,16,20}$ Attention to adherence is especially important in frail elderly patients. There is an ongoing discussion in the literature on the influence of GS and/or its components on the level of adherence. In the present study, FS coexisted with hypertension in $63.9 \%$ of patients.
Koizumi et al evaluated the association between hypertension and prevalence of FS and confirmed that impaired mobility (inability to walk for more than $15 \mathrm{~min}$ without rest), weight loss of more than $2-3 \mathrm{~kg}$ in the past 6 months, difficulty in eating solid food, and limitations in performing complex activities of daily living were correlated with prevalence, treatment, and control of hypertension. ${ }^{37}$

In other studies on frailty, women were more frequently affected than man and age was found as determinant of frailty. ${ }^{38,39}$ This has not been confirmed in our study because the number of women was similar in both the groups (frail vs non-frail).

The lack of adherence may negatively affect the course of disease, especially in elderly patients. Many factors can interfere with adherence in this group of patients, eg, cognitive impairment, lack of knowledge about illness and medication, and coexistence of frailty.

Talegawkar et al assessed the association between frailty and adherence to Mediterranean diet and concluded that subjects without FS had higher level of adherence to diet recommendations than frailty patients..$^{40}$ On the other hand, Chao et al demonstrated that, contrary to our research results, in a group of chronically dialyzed patients, the absence of frailty/pre-frailty was significantly associated with poorer medication adherence. ${ }^{13}$ Results obtained by 
Chao et al are surprising as they defy the assumption that frailty negatively affects the level of adherence. ${ }^{13}$ However, the authors explain this fact with the old age of patients, which also in other studies appears as a well-established factor contributing to better adherence. Additionally, elderly patients might be more concerned about their health and complexity of comorbidities, which make them more focused on adhering to complex therapy regimens. ${ }^{13} \mathrm{Wu}$ et al, in turn, believe that elderly patients with FS and cognitive disorders may not report the level of adherence as accurately as younger patients, which may be the cause of artificially high results. ${ }^{41}$

But the authors rightly stress that the connection between poor adherence to therapy and the level of cognitive function is not well documented in clinical practice, and contradictory results may stem from an insufficient representation of elderly patients with cognitive disorders in the majority of adherence studies $^{42,43}$ and difficulty in differentiating between simple forgetfulness and cognitive disorders. ${ }^{44}$

Other studies on patients with AF demonstrated that cognitive disorders were a significant determinant of poorer adherence to pharmacological recommendations, ${ }^{18}$ and in the research by Salas et al, cognitive function was an independent predictor of compliance with antihypertensive drugs in elderly patients who are living alone. ${ }^{45}$

In the present study, we proved that frailty negatively affects adherence in elderly hypertensive patients but only in the univariate analysis. To our best knowledge, studies on association between FS and adherence in patients with hypertension have not been conducted to date.

Medication adherence is considered essential for management of hypertension as is patient cooperation. In our study, we found that patients' adherence was lower in the frail group. Among factors that negatively affected adherence were loneliness and some frailty determinants according to Tilburg scale such as being alone, death of the beloved one, serious illness, serious illness in a partner, and divorce or ending of a relationship during the past year.

Additionally in the study by Talegawkar et al, the lack of adherence was related to decrease in physical activity and difficulty in walking, which is similar to our findings where impaired mobility and physical component of Tilburg questionnaire negatively affected adherence. ${ }^{40}$

In the present study, coexistence of FS as measured by Tilburg scale was the determinant of worse adherence. It is worth noting that in our study, the social, physical, and physical frailty components were also the determinants of lower adherence to antihypertensive treatment. Regression analysis of answers from Tilburg questionnaire showed that knowledge about complications of hypertension and satisfaction with the home environment are predictors of good adherence, while lack of support from others and loneliness are predictors of bad adherence. The role of social support in care of frail patients is therefore a crucial element in health care planning. ${ }^{46,47}$ In the studies from the literature, patients living with families had higher adherence than those living alone. ${ }^{34}$ Also, elderly patients using the possibility of transportation as well as care and support from caregivers more often adhered to treatment recommendation than patient with limited support. ${ }^{48,49}$ Other authors have reported that low level of social support is associated with increased risk for FS. ${ }^{50,51}$ Also, low socioeconomic status contributes to development of frailty. ${ }^{50,52}$ Moreira et al reported significant association between marital status and development of frailty; in their research, single men and widowers had increased risk for FS. ${ }^{53}$ In the present study, satisfaction with the home environment and living in a relationship stimulated better adherence.

Reports from the literature show outcomes on positive effect of social support on the course of the disease and recovery in cardiac patients. ${ }^{54}$ Support experienced by patients accelerates the recovery process and therefore becomes an additional help, increasing natural forces in the fight against diseases and enables them to recover to full health or live with a disease. In the meta-analysis performed by Scheurer et al, similar to our finding, positive role of social support in adherence was documented. ${ }^{55}$ In other studies, the level of adherence was considerably higher among patients with social support and living in supportive families, while it was considerably lower in patients from conflicted families. Outcomes of research by DiMatteo et al correspond with our results and reveal that marriage or living in a partnership is a factor improving adherence. ${ }^{34}$

One of the components of GS is polypharmacy. In our study, we evaluated the relation between polypharmacy and adherence. Similarly to our previous research, ${ }^{16}$ we did not observe any correlation in this respect. However, there are authors who have demonstrated that polypharmacy is an important barrier to adherence. In the present study, an independent predictor of good adherence was knowledge about complications of untreated hypertension.

Systematic identification of adherence determinants, including frailty, is important in terms of risk stratification and necessity of introducing multidisciplinary interventions to prevent symptoms of frailty.

\section{Conclusion}

Frailty is highly prevalent among elderly hypertensive patients. Higher level of frailty among elderly patients may 
be considered as a determinant of lower adherence. However, social support and knowledge about complications of untreated hypertension are the most important independent determinants of adherence to pharmacological treatment.

\section{Implications for practice}

Potential barriers to adherence should be assessed and addressed, with a particular reference to engagement of social support systems. Understanding the concept of frailty may help to optimize medication prescribed for older people and target health care resources more effectively and appropriately, improving the care of all older people with hypertension. When frailty can be measured with precision, we can start to explore which interventions are the most beneficial for patients according to their different levels of resilience.

\section{Study limitations}

The analysis of treatment of other chronic diseases apart from hypertension as well as possible polypharmacy, drug interactions, and side effects was not included; however, these factors may also contribute to the level of adherence and severity of frailty among elderly patients with hypertension.

\section{Acknowledgment}

Use of the CMMAS is protected by US and International copyright laws. Permission for use is required. A license agreement is available from: Donald E Morisky, MMAS Research (MORISKY) 16636 159th Place SE, Renton WA 98058,dmorisky@gmail.com.

\section{Disclosure}

The authors report no conflicts of interest in this work.

\section{References}

1. Chobanian AV, Bakris GL, Black HR, et al. The Seventh Report of the Joint National Committee on Prevention, Detection, Evaluation, and Treatment of High Blood Pressure: the JNC 7 report. JAMA. 2003;289(19):2560-2572.

2. Kocelak P, Olszanecka-Glinianowicz M, Owczarek A, et al. Plasma visfatin/nicotinamide phosphoribosyltransferase levels in hypertensive elderly - results from the PolSenior substudy. J Am Soc Hypertens. 2015;9(1):1-8.

3. Tykarski A, Narkiewicz K, Gaciong Z, et al. 2015 guidelines for the management of hypertension. Recommendation of the Polish Society of Hypertension - short version. Kardiol Pol. 2015;73(8):676-700.

4. Grodzicki T, Narkiewicz K. New guidelines for the management of arterial hypertension - VII report of Joint National Committee and the guidelines of the European Society of Hypertension - European Society of Cardiology. Arterial Hypertension. 2003;7(2):99-104.
5. Mancia G, Fagard R, Narkiewicz R, et al. 2013 ESH/ESC guidelines for the management of arterial hypertension: the Task Force for the management of arterial hypertension of the European Society of Hypertension (ESH) and of the European Society of Cardiology (ESC). J Hypertension. 2013;31(7):1281-1357.

6. Corrao G, Rea F, Ghirardi A, Soranna D, Merlino L, Mancia G. Adherence with antihypertensive drug therapy and the risk of heart failure in clinical practice. Hypertension. 2015;66(4):742-749.

7. Rajpura J, Nayak R. Medication adherence in a sample of elderly suffering from hypertension: evaluating the influence of illness perceptions, treatment beliefs, and illness burden. J Manag Care Pharm. 2014;20(1):58-65.

8. Ross S, Walker A, MacLeod MJ. Patient compliance in hypertension: role of illness perceptions and treatment beliefs. J Hum Hypertens. 2004;18(9):607-613.

9. Inouye SK, Studenski S, Tinetti ME, Kuchel GA. Geriatric syndromes: clinical, research, and policy implications of a core geriatric concept. J Am Geriatr Soc. 2007;55(5):780-791.

10. Fried LP, Tangen CM, Walston J, et al. Frailty in older adults: evidence for a phenotype. J Gerontol A Biol Sci Med Sci. 2001;56(3): M146-M156.

11. Aminzadeh F, Dalziel WB, Molnar FJ. Targeting frail older adults for outpatient comprehensive geriatric assessment and management services: an overview of concepts and criteria. Rev Clin Gerontol. 2002;12:82-92.

12. Espinoza S, Walston JD. Frailty in older adults: insights and interventions. Cleve Clin J Med. 2005;72:1105-1112.

13. Chao CT, Huang JW; COGENT (COhort of Geriatric Nephrology in NTUH) study group. Geriatric syndromes are potential determinants of the medication adherence status in prevalent dialysis patients. PeerJ. 2016; 4:e2122

14. Sarafidis PA, Bakris GL. Resistant hypertension: an overview of evaluation and treatment. $J$ Am Coll Cardiol. 2008;52:1749-1757.

15. Whitworth JA; World Health Organization, International Society of Hypertension Writing Group. 2003 World Health Organization (WHO)/ International Society of Hypertension (ISH) statement on management of hypertension. J Hypertens. 2003;21(11):1983-1992.

16. Jankowska-Polańska B, Blicharska K, Uchmanowicz I, Morisky DE. The influence of illness acceptance on the adherence to pharmacological and non-pharmacological therapy in patients with hypertension. Eur $J$ Cardiovasc Nurs. Epub 2016 Jan 7.

17. Holt E, Joyce C, Dornelles A, et al. Sex differences in barriers to antihypertensive medication adherence: findings from the cohort study of medication adherence among older adults. J Am Geriatr Soc. 2013; 61:558-564.

18. Jankowska-Polańska B, Katarzyna L, Lidia A, Joanna J, Dudek K, Izabella $\mathrm{U}$. Cognitive function and adherence to anticoagulation treatment in patients with atrial fibrillation. J Geriatr Cardiol. 2016;13(7): 559-565.

19. Burnier M. Medication adherence and persistence as the cornerstone of effective antihypertensive therapy. Am J Hypertens. 2006;19: $1190-1196$.

20. Krousel-Wood M, Thomas S, Muntner P, Morisky D. Medication adherence: a key factor in achieving blood pressure control and good clinical outcomes in hypertensive patients. Curr Opin Cardiol. 2004;19:357-362.

21. Carter BL, Foppe van Mil JW. Comparative effectiveness research: evaluating pharmacist interventions and strategies to improve medication adherence. Am J Hypertens. 2010;23:949-955.

22. Kamran A, Sadeghieh AS, Biria M, Malepour A, Heydari H. Determinants of patient's adherence to hypertension medications: application of health belief model among rural patients. Ann Med Health Sci Res. 2014;4:922-927.

23. Irvin MR, Shimbo D, Mann DM, et al. Prevalence and correlates of low medication adherence in apparent treatment - resistant hypertension J Clin Hypertens (Greenwich). 2012;14:694-700.

24. Krousel-Wood MA, Muntner P, Islam T, Morisky DE, Webber LS. Barriers to and determinants of medication adherence in hypertension management: perspective of the cohort study of medication adherence among older adults (CoSMO). Med Clin North Am. 2009;93:753-769. 
25. Lee GK, Wang HH, Liu KQ, Cheung Y, Morisky DE, Wong MC. Determinants of medication adherence to antihypertensive medications among a Chinese population using Morisky Medication Adherence Scale. PLoS One. 2013;8:e62775.

26. Folstein MF, Folstein SE, McHugh PR. "Mini-mental state". A practical method for grading the cognitive state of patients for the clinician. J Psychiatr Res. 1975;12(3):189-198.

27. Herr M, Robine JM, Pinot J, Arvieu JJ, Ankri J. Polypharmacy and frailty: prevalence, relationship, and impact on mortality in a French sample of 2350 old people. Pharmacoepidemiol Drug Saf. 2015;24:637-646.

28. Uchmanowicz I, Jankowska-Polańska B, Łoboz-Rudnicka M, Manulik S, Łoboz-Grudzień K, Gobbens RJ. Cross-cultural adaptation and reliability testing of the Tilburg frailty indicator for optimizing care of Polish patients with frailty syndrome. Clin Interv Aging. 2014;9:997-1001.

29. Gobbens RJ, van Assen MA, Luijkx KG, Schols JM. The predictive validity of the Tilburg frailty indicator: disability, health care utilization, and quality of life in a population at risk. Gerontologist. 2012;52(5): 619-631.

30. Morisky DE, Ang A, Krousel-Wood M, Ward HJ. Predictive validity of a medication adherence measure in an outpatient setting. J Clin Hypertens (Greenwich). 2008;10(5):348-354.

31. Krousel-Wood MA, Islam T, Webber LS, Re RS, Morisky DE, Muntner P. New Medication Adherence Scale Versus Pharmacy Fill Rates in Seniors with Hypertension. Am J Manag Care. 2009; 15(1):59-66.

32. Morisky DE, DiMatteo MR. Improving the measurement of selfreported medication nonadherence: Final response. J Clin Epidem. 2011;64:258-263.

33. Wroth TH, Pathman DE. Primary medication adherence in a rural population: the role of the patient-physician relationship and satisfaction with care. J Am Board Fam Med. 2006;19(5):478-486.

34. DiMatteo MR, Giordani PJ, Lepper HS, Croghan TW. Patient adherence and medical treatment outcomes: a meta-analysis. Med Care. 2002; 40(9):794-811.

35. Sokol MC, McGuigan KA, Verbrugge RR, Epstein RS. Impact of medication adherence on hospitalization risk and healthcare cost. Med Care. 2005;43(6):521-530.

36. Piette JD, Heisler M, Krein S, Kerr EA. The role of patient-physician trust in moderating medication nonadherence due to cost pressures. Arch Intern Med. 2005;165(15):1749-1755.

37. Koizumi Y, Hamazaki Y, Okuro M, et al. Association between hypertension status and the screening test for frailty in elderly communitydwelling Japanese. Hypertens Res. 2013;36(7):639-644.

38. Vermeulen J, Neyens JC, van Rossum E, Spreeuwenberg MD, de Witte LP. Predicting ADL disability in community-dwelling elderly people using physical frailty indicators: a systematic review. BMC Geriatr. 2011; $11: 33$.

39. Gobbens RJ, van Assen MA. Frailty and its prediction of disability and health care utilization: the added value of interviews and physical measures following a self-report questionnaire. Arch Gerontol Geriatr. 2012; 55(2):369-379.

40. Talegawkar SA, Bandinelli S, Bandeen-Roche K, et al. A higher adherence to a Mediterranean-style diet is inversely associated with the development of frailty in community-dwelling elderly men and women. J Nutr. 2012;142(12):2161-2166.
41. Wu YH, Liu LK, Chen WT, et al. Cognitive function in individuals with physical frailty but without dementia or cognitive complaints: results from the I-Lan longitudinal aging study. J Am Med Dir Assoc. 2015;16(10):899.e9-e16.

42. Okuno J, Yanagi $\mathrm{H}$, Tomura $\mathrm{S}$. Is cognitive impairment a risk factor for poor compliance among Japanese elderly in the community? Eur J Clin Pharmacol. 2001;57:589-594.

43. Rauch G, Veltkamp R. Cognitive impairment is not a predictor of failure to adhere to anticoagulation of stroke patients with atrial fibrillation. Cerebrovasc Dis. 2015;39(5-6):325-331.

44. Arlt S, Lindner R, Rosler A, von Rentein-Kruse W. Adherence to medication in patients with dementia: predictors and strategies for improvement. Drugs Aging. 2008;25:1033-1047.

45. Salas M, In't Veld BA, van der Linden PD, Hofman A, Breteler M, Stricker BH. Impaired cognitive function and compliance with antihypertensive drugs in elderly: the Rotterdam Study. Clin Pharmacol Ther. 2001;70(6):561-566.

46. Grant AB, Seixas A, Frederickson K, et al. Effect of expectation of care on adherence to antihypertensive medications among hypertensive Blacks: analysis of the Counseling African Americans to Control Hypertension (CAATCH) Trial. J Clin Hypertens (Greenwich). 2016;18(7): 690-696.

47. Magrin ME, D'Addario M, Greco A, et al. Social support and adherence to treatment in hypertensive patients: a meta-analysis. Ann Behav Med. 2015;49(3):307-318.

48. Kipnis V, Subar AF, Midthune D, et al. Structure of dietary measurement error: results of the OPEN biomarker study. Am J Epidemiol. 2003;158(1):14-21.

49. Robinson S, Cooper C, Aihie Sayer A. Nutrition and sarcopenia: a review of the evidence and implications for preventive strategies. J Aging Res. 2012;2012:510801.

50. Lurie I, Myers V, Goldbourt U, Gerber Y. Perceived social support following myocardial infarction and long-term development of frailty. Eur J Prev Cardiol. 2015;22(10):1346-1353.

51. Guerra HL, Firmo JO, Uchoa E, Lima-Costa MF. The Bambui Health and Aging Study (BHAS): factors associated with hospitalization of the elderly. Cad Saude Publica. 2001;17(6):1345-1356.

52. Myers V, Drory Y, Goldbourt U, Gerber Y. Multilevel socioeconomic status and incidence of frailty post myocardial infarction. Int J Cardiol. 2014;170(3):338-343.

53. Moreira VG, Lourenço RA. Prevalence and factors associated with frailty in an older population from the city of Rio de Janeiro, Brazil: the FIBRA-RJ Study. Clinics (Sao Paulo). 2013;68(7):979-985.

54. Haskell WL. Cardiovascular disease prevention and lifestyle interventions: effectiveness and efficacy. J Cardiovasc Nurs. 2003;18(4): 245-255.

55. Scheurer D, Choudhry N, Swanton KA, Matlin O, Shrank W. Association between different types of social support and medication adherence. Am J Manag Care. 2012;18(12):e461-e467.
Clinical Interventions in Aging

\section{Publish your work in this journal}

Clinical Interventions in Aging is an international, peer-reviewed journal focusing on evidence-based reports on the value or lack thereof of treatments intended to prevent or delay the onset of maladaptive correlates of aging in human beings. This journal is indexed on PubMed Central, MedLine,

\section{Dovepress}

CAS, Scopus and the Elsevier Bibliographic databases. The manuscript management system is completely online and includes a very quick and fair peer-review system, which is all easy to use. Visit http://www.dovepress. com/testimonials.php to read real quotes from published authors. 